\title{
Nanoplugging Performance of Hyperbranched Polyamine as Nanoplugging Agent in Oil-Based Drilling Fluid
}

\author{
Gang Xie, ${ }^{1}$ Pingya Luo, ${ }^{1}$ Mingyi Deng, ${ }^{1}$ and Zheng Wang ${ }^{1,2}$ \\ ${ }^{1}$ State Key Laboratory of Oil \& Gas Reservoir Geology and Exploitation, Southwest Petroleum University, Chengdu, \\ Sichuan 610500, China \\ ${ }^{2}$ Oil and Gas Engineering Institute, Southwest Petroleum University, Chengdu, Sichuan 610500, China
}

Correspondence should be addressed to Pingya Luo; luopy@swpu.edu.cn

Received 15 August 2015; Accepted 25 October 2015

Academic Editor: Victor M. Castaño

Copyright (C) 2015 Gang Xie et al. This is an open access article distributed under the Creative Commons Attribution License, which permits unrestricted use, distribution, and reproduction in any medium, provided the original work is properly cited.

\begin{abstract}
A hyperbranched polyamine was synthesized by self-condensing vinyl polymerization with divinyl sulfone, N-phenyl-pphenylenediamine, by $\mathrm{A}_{2}+\mathrm{BB}_{2}^{\prime}$ approach. The hyperbranched polyamine was characterized by FT-IR, TGA, and phase analysis light scanning. Average grain diameter of hyperbranched polyamine was $36.7 \mathrm{~nm}$. Hyperbranched polyamine has good thermal stability. Hyperbranched polyamine (HBPA) was employed successfully as nanoplugging agent in oil-based drilling fluid system, which could plug nanopore formation in shale formation. HBPA has a little effect on rheological properties of oil-based drilling fluid and the $\mathrm{FL}_{\mathrm{API}}$ and $\mathrm{FL}_{\mathrm{HTHP}}$ decreased dramatically with an increase of hyperbranched polyamine. Emulsion-breaking voltage has a slight increase, which is beneficial to maintain stability of oil-based drilling fluid. When the HBPA concentration is greater than $1 \mathrm{wt} \%$, plugging rate of oil-based drilling fluid for artificial core is close to $100 \%$ and the permeability recovery value can reach 99.7\% after adding $1 \mathrm{wt} \% \mathrm{HBPA}$, which prove that HBPA has an excellent plugging performance.
\end{abstract}

\section{Introduction}

Drilling is linked to drilling fluid that can often cause borehole instability. Borehole instability often leads to various kinds of problems such as hole collapse, tight hole, stuck pipe, bit balling, high torque, and drag, which can increase drilling time and costs [1]. Serious problems mainly occur in shale (principally clay), particularly in water-sensitive shale formations, which account for $75 \%$ of all formations drilled by the oil and gas industry $[2,3]$. Horizontal well drilling has become the main development of drilling shale formation. In order to prevent the borehole wall collapse of shale gas horizontal well, strong inhibitory oil-based drilling fluid was used. However, oil-based drilling fluid cannot solve the problem of borehole wall instability very well. The essential reason is hydraulic fracturing effect. When oil phase filtrate invades into the cracks, makes the crack open, and greatly reduces the friction of the joint surface at the same time, the collapse pressure rose significantly. If the filtrate cannot be blocked effectively into the cracks, the collapse pressure cannot be prevented. Therefore, whether water-based drilling fluid or oil-based drilling fluid strengthen the blocking that prevent filtrate into the formation of micro-cracks and reduce the formation collapse pressure is the key of drilling shale gas horizontal well, which can improve the pressure-bearing capability of borehole wall and expand the safe density window of drilling fluid. With the combination of nanotechnology and drilling fluid technology, nanomaterials as plugging agent can enhance its plugging effectiveness [4-6]. Nanoplugging particles enter the cracks a certain distance to form internal partition wall and the cracks can be effectively sealed, which prevent drilling fluid filtrate permeate into microcracks of shale wellbore, block the contact of mud filtrate and formation, reduce the formation collapsed pressure, improve wellbore pressure-bearing ability, and expand the safe density window of drilling fluid. In the recent study, fewer studies have focused on 1 100 nm of microfracture plugging. Effective plug for nanopore is the key of wellbore stability in shale formation that has a large number of nanoscale microfracture. Therefore, research of nanosealing materials 
can help to study the sealing mechanism and the borehole instability in the process of drilling.

Nanoplugging materials have proven to be an important effect on decreasing the permeability of shale formation, helping to resist fluid invasion and dying out of the shale walls $[7,8]$. Compared to the influence of shale permeability before and after nanoparticles were added in the drilling fluid to evaluate the plugging efficiency of nanoparticles, it is found that the blocking performance of nanoparticles is better than conventional polymer $[9,10]$. Recently, various types of materials, that is, nanosilica [11], nanographene [12], and cellulose nanoparticle [13], have been applied as high performance nanosealing materials in drilling fluids. For example, it was reported that the cellulose nanoparticles, including cellulose nanocrystals and cellulose nanofibers, showed good rheological properties [14]. When nanoparticles are passed through a low permeability media with nanopores, the nanoparticles have no effective straining $[15,16]$. Baker Hughes Corp. had prepared a novel style of nanosized insoluble deformable polymer. This nanometer polymer could infiltrate nanosized pores in shale formation, sedimentate on the surface, and shape low permeable filter cake. In addition, salt resistance was still elevated and was environmentally friendly drilling fluid. As a consequence, the deformable polymer could seal nanosized microfractures and pore throats in shale formation, decrease the permeability of filtrate penetrate into the formations, lower pressure transmission, and block borehole collapse [17]. Blocking materials have a variety of grain sizes for oil-base drilling fluid that need to be optimized. A variety of sealing mechanism can be utilized to block microcracks and make the drilling fluid form a layer of isolation film near borehole wall, enhancing the plugging effect of oil-based drilling fluid and maintaining borehole wall stability, which is expected to solve borehole wall instability problem that use oil-based drilling fluid to drill shale gas horizontal well.

Hyperbranched polymers exhibit three-dimensional dentritic architecture, very low viscosity, high solubility, and plenty of functional groups at the terminal units [18]. An increasing number of studies have a focus on the potential value of hyperbranched polymers in the oil and gas industry [19]. Owing to the three-dimensional dentritic architecture of hyperbranched polymers, hyperbranched polymers were used as nanometer plugging agent such as hyperbranched polyamine which can enhance its plugging effectiveness and hyperbranched polymers had no effect on the drilling fluid rheology. Therefore, hyperbranched polyamine would become a progressing nanometer plugging agent for plugging nanopore in oil-based drilling fluid system. In this paper, the synthesis and properties of hyperbranched polyamine and its nanoplugging properties are described in detail.

\section{Materials and Methods}

2.1. Materials. Divinyl sulfone come from Chengdu Micxy Chemical Co., Ltd., was used after purification by vacuum distillation. N-Phenyl-p-phenylenediamine come from Chengdu Changzheng Co., Ltd., was used. N,N-Dimethylformamide (DMF) as organic solvents was used. White oil, emulsifier, calcium oxide, fluid loss additive, wetting agent, shear strength improving agent, calcium chloride, and barite are industrial products.

2.2. Synthesis and Characterization of Hyperbranched Polyamine. The Fourier transform infrared (FTIR) spectra of the polymer were determined with Beijing Rayleigh Analytical Instrument Co., Ltd. Thermogravimetric analysis (TGA) was carried out in METTLER TGA/DSC at a nitrogen flow rate of $60 \mathrm{~mL} / \mathrm{min}$. The polymer was heated at a heating rate of $10^{\circ} \mathrm{C} / \mathrm{min}$ from 30 to $800^{\circ} \mathrm{C}$. The particle size analysis was carried out in Brookhaven ZetaPALS.

2.3. Fluid Preparation and Thermal Aging Tests. The based mud (white oil $+3.0 \mathrm{wt} \%$ emulsifier $+2.0 \mathrm{wt} \%$ calcium oxide $+2.0 \mathrm{wt} \%$ fluid loss additive $+1.0 \mathrm{wt} \%$ wetting agent $+1.0 \mathrm{wt} \%$ shear strength improving agent $+25 \mathrm{wt} \%$ calcium chloride + barite) was made by stirring at a high speed of 10,000 rpm for $20 \mathrm{~min}$ to generate homogeneous dispersions. HBPA was added into the based mud, stirring for $20 \mathrm{~min}$ at a high speed of $10,000 \mathrm{rpm}$ at room temperature. Thermal aging experiments of based mud HBPA fluid were carried out by GW300 Roller furnace from Qingdao Jiaonan Tongchun Machinery Plant, China, through hot rolling at the appointed temperature $180^{\circ} \mathrm{C}$ for $16 \mathrm{~h}$. Oil-based drilling fluids property tests were measured before and after thermal aging experiments.

2.4. Fluid Property Tests. The rheological properties were tested with a ZNN-D6 rotating viscometer from Qingdao Jiaonan Tongchun Machinery Petroleum Instrument Ltd., China, at room temperature. Geometry of viscometer spinning rod is shown in Figure 1. The dimensions of viscometer spinning rod are designed strictly according to the standard of American Petroleum Institute (API). Rotating viscometer has six speed changes of $3,6,100,200,300$, and $600 \mathrm{rpm}$, which correspond to six different shear rates of 5, 10, 170, 340, 511, and $1022 \mathrm{~s}^{-1}$, respectively. Therefore, the range of shear rate is $5 \sim 1022 \mathrm{~s}^{-1}$. The probe of rotating viscometer consists of an inner cylinder and an outer cylinder of concentric rotating. When drilling fluid is in the annular space between inner cylinder and outer cylinder, outer cylinder rotates with a constant speed. The outer cylinder produces a torque for inner cylinder through drilling fluid, which causes the inner cylinder connected with torsion spring to rotate a corresponding angle. According to Newton's law, the angle is proportional to the viscosity of liquid. Therefore, the measurement of liquid viscosity becomes the measurement of angle. The angle is reflected in the dial reading. These rheological parameters such as apparent viscosity (AV), plastic viscosity (PV), and yield point (YP) were calculated from 600 to $3 \mathrm{rpm}$ readings through the following formulas from American Petroleum Institute (API) that recommended practice of standard procedure for field testing drilling fluids [20]:

$$
\begin{aligned}
& \text { apparent viscosity }(\mathrm{AV})=\varphi 600 / 2(\mathrm{MPa} \cdot \mathrm{s}) \text {; } \\
& \text { plastic viscosity }(\mathrm{PV})=\varphi 600-\varphi 300(\mathrm{MPa} \cdot \mathrm{s}) \text {; } \\
& \text { yield point }(\mathrm{YP})=(\varphi 300-\mathrm{PV}) / 2\left(\mathrm{~N} / \mathrm{m}^{2}\right) .
\end{aligned}
$$

2.5. Synthesis. Ten mmol of N-phenyl-p-phenylenediamine was placed in a $100 \mathrm{~mL}$ three-necked round bottom flask. 


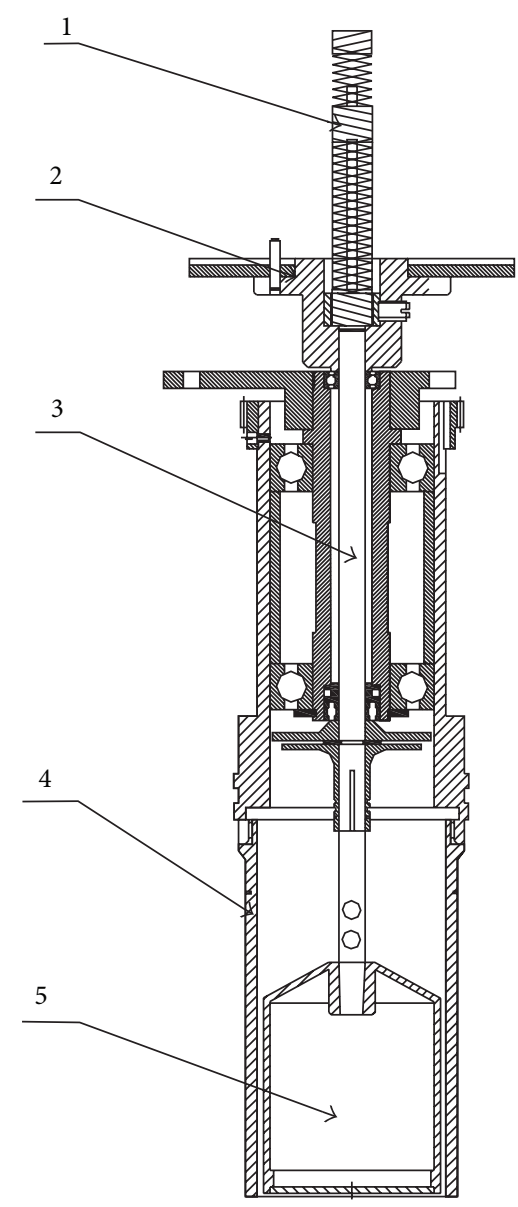

FIGURE 1: The geometry of viscometer spinning rod. Note: 1: spring assembly; 2: dial components; 3: inner tank shaft; 4: outer cylinder; 5: inner cylinder.

When the reaction mixture was totally dissolved in $20 \mathrm{~mL}$ of $\mathrm{N}, \mathrm{N}$-dimethylformamide, $20 \mathrm{mmol}$ of divinyl sulfone was slowly added under $\mathrm{N}_{2}$ purge and then bubbled into nitrogen for $10 \mathrm{~min}$. The mixture was heated to $50^{\circ} \mathrm{C}$ for $3 \mathrm{~h}$. The reaction mixture was slowly poured into $500 \mathrm{~mL}$ of methanol and then the precipitate was collected. The precipitate was purified by reprecipitation with $500 \mathrm{~mL}$ of methanol. The product was dried under vacuum at $65^{\circ} \mathrm{C}$ for $24 \mathrm{~h}$. The powdery product was obtained.

\section{Results and Discussion}

3.1. Synthesis of Hyperbranched Polyamine. Hyperbranched polyamine (HBPA) as nanoplugging agent was synthesized by using an $\mathrm{A}_{2}+\mathrm{BB}_{2}^{\prime}$ method (Figure 2). $\mathrm{A}_{2}$ monomer is divinyl sulfone. $\mathrm{BB}_{2}^{\prime}$ monomer is N-phenyl-p-phenylenediamine for this reaction. Vinyl groups of divinyl sulfone react rapidly with secondary amino groups of N-phenylp-phenylenediamine compared to vinyl groups of divinyl sulfone with primary amino groups of N-phenyl-p-phenylenediamine, generating $\mathrm{AB}_{2}^{\prime}$ monomers. $\mathrm{AB}_{2}^{\prime}$ type monomers as the intermediate were polymerized further, which generate branched polyamine [21]. This excellent choice of reaction conditions such as proper ratio, appropriate concentration, and slowly adding $\mathrm{A}_{2}$ monomers could successfully avoid gelation. The mole ratio of $\mathrm{A}_{2}$ and $\mathrm{BB}_{2}^{\prime}$ monomers was $2: 1$ and the $\mathrm{A}_{2}$ monomer was added slowly into a dilute solution $(<10 \%, \mathrm{w} / \mathrm{v})$ of $\mathrm{BB}_{2}^{\prime}$ the monomer in DMF solvent. The yield of hyperbranched polyamine was greater than $84 \%$.

3.2. Characterization of Hyperbranched Polyamine. The FTIR spectrum (Figure 3) of the polymer shows various peaks to the ideal structure of the copolymer. $3034 \mathrm{~cm}^{-1}$ is benzene ring $=\mathrm{CH}$ stretching vibration absorption peak. $1597 \mathrm{~cm}^{-1}$ is benzene ring $\mathrm{C}=\mathrm{C}$ stretching vibration absorption peak. $838 \mathrm{~cm}^{-1}$ is characteristic absorption peak of 1,4 -substituted benzene. $692 \mathrm{~cm}^{-1}$ is characteristic absorption peak of single substituted benzene, which proves that nanometer blocking agent polymer has benzene ring. $1327 \mathrm{~cm}^{-1}$ is $\mathrm{O}=\mathrm{S}=\mathrm{O}$ asymmetric stretching vibration peak and $1121 \mathrm{~cm}^{-1}$ is $\mathrm{O}=\mathrm{S}=\mathrm{O}$ symmetrical stretching vibration peak $[22,23] .3465 \mathrm{~cm}^{-1}$ and $3378 \mathrm{~cm}^{-1}$ are stretching vibration absorption peaks of aromatic primary amine. $1298 \mathrm{~cm}^{-1}$ is stretching vibration absorption peak of aromatic amine C-N and $1597 \mathrm{~cm}^{-1}$ is the deformation vibration peak of primary amines. These prove that plugging agent was synthesized by N-phenyl-pphenylenediamine and divinyl sulfone. Thermogravimetric analysis curve shows that benzene ring enhances the rigidity of polymer chains and weakens the thermal motion of polymer chains. So polymer has good thermal stability.

3.3. Thermostability of Hyperbranched Polyamine. Hyperbranched polyamine has a high solubility in oil. Figure 4 is the thermogravimetric curve of hyperbranched polyamine. The weight loss of hyperbranched polyamine about $0.95 \%$ at $209^{\circ} \mathrm{C}$ was owing to the loss of absorbed water or crystalliferous water. The degradation of hyperbranched polyamine started at about $299.13^{\circ} \mathrm{C}$ and happened in the first step. There was no obvious thermal decomposition when the temperature was under $299.13^{\circ} \mathrm{C}$. Benzene ring has a good thermal stability due to its domain structure. Compared to common alkyl carbon chain of prepared polymers, the c-c bond of benzene ring has an extreme rigidity and thermal motion of the molecular chain will be blocked under an environment of high temperature, which would improve the high-temperature resistance of polymer. With the increase of temperature, the weight of hyperbranched polyamine started to decrease due to the decomposition of the polymer. Almost $72.31 \%$ weight losses have occurred at $489.7^{\circ} \mathrm{C}$. It was demonstrated that hyperbranched polyamine has a strong temperature-resistance and its decomposition temperature is higher than $299^{\circ} \mathrm{C}$.

3.4. Grain Size Distribution. Recently, a more sensitive technique, phase analysis light scattering (PALS), has been developed with particular benefits for application to nonpolar systems [24]. The technique, phase analysis light scattering (PALS), is based upon classical laser-Doppler electrophoresis but employs signal processing of the time domain phase information within the scattered light signal, rather than analysis of its frequency spectrum [25]. Compared with the 


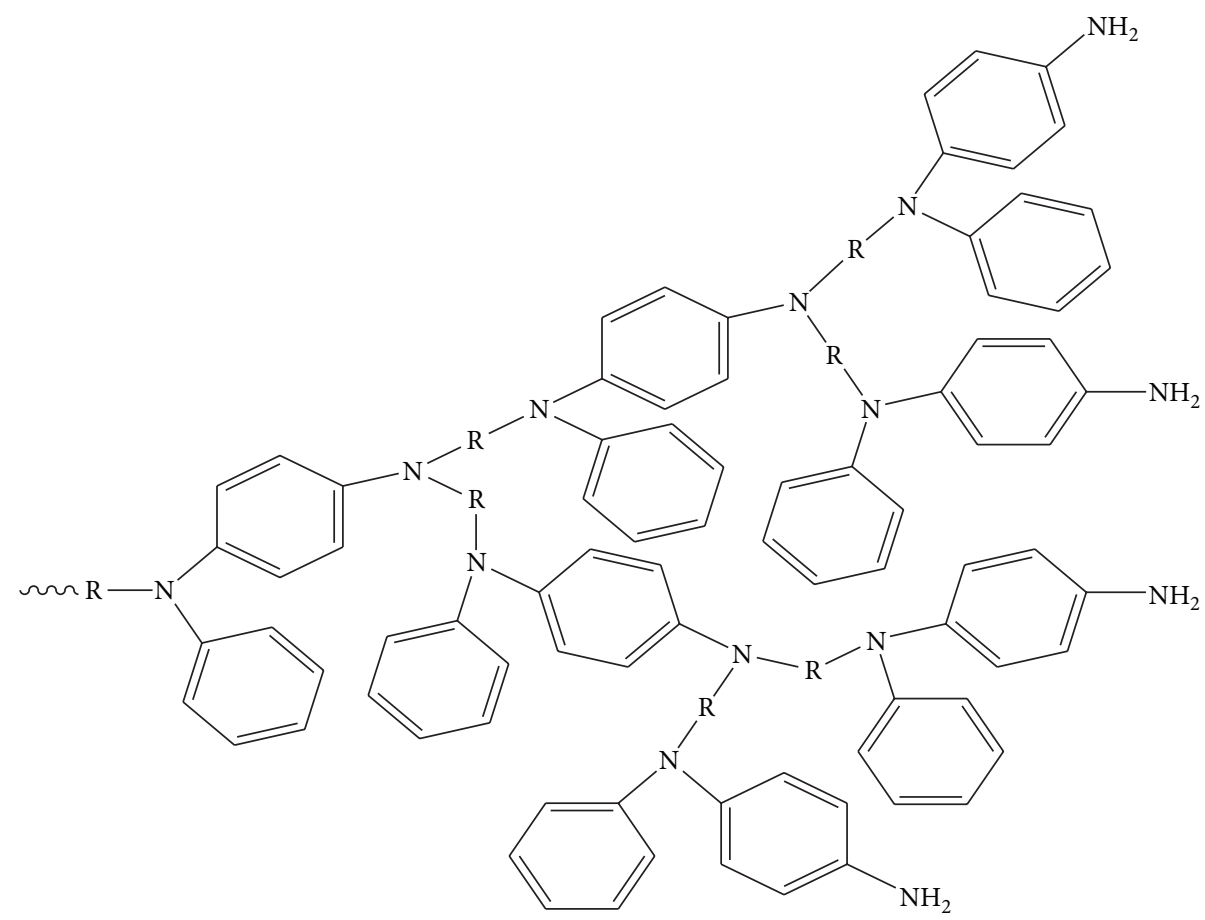

(R: $\mathrm{CH}_{2}=\mathrm{CHSO}_{2} \mathrm{CH}=\mathrm{CH}_{2}$ )

FIGURE 2: Chemical structure of hyperbranched polyamine.

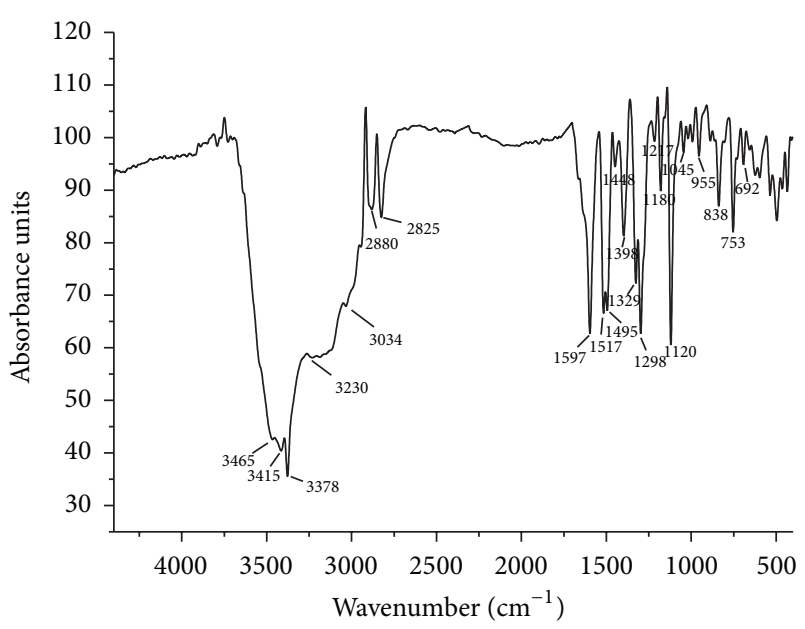

FIGURE 3: Fourier transform infrared (FTIR) spectroscopy of hyperbranched polyamine.

traditional light scattering method based on the technology of frequency shift, the sensitivity of phase analysis light scattering can be enhanced by 1000 times. Firstly, $1 \mathrm{wt} \%$ HBPA is dissolved in normal hexane. Then HBPA solution is collected in the cuvette through $450 \mathrm{~nm}$ filters. Next, the cuvette is placed in the pool of the measurement. Finally, choose normal hexane as measuring media and start measuring. The particle size of nanoblocking polymer is determined by the ZetaPALS laser particle size instrument of Brookhaven, which is shown in Figure 5. Figure 5 shows that the grain

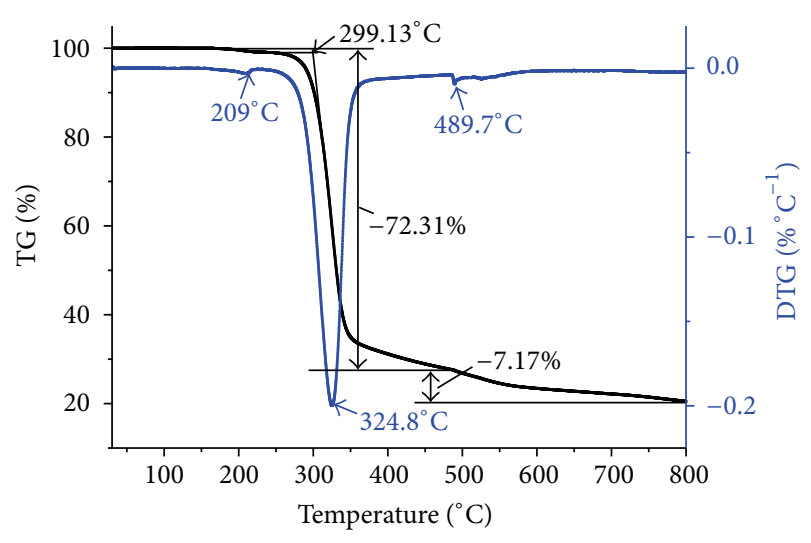

FIgURE 4: Thermogravimetric analysis of hyperbranched polyamine.

size distribution of the polymer is more concentrated and the curve of grain size distribution presents parabolic type. The grain size distribution is between $3 \sim 350 \mathrm{~nm}$ and the average grain diameter is $36.7 \mathrm{~nm}$. The grain size of polymer particles smaller than $100 \mathrm{~nm}$ accounted for $80 \%$, which can block the microfracture of different nanoscale.

\subsection{Plugging Effect Evaluation}

3.5.1. Rheological and Filtrate Properties of HBPA in the OilBased Drilling Fluid. The change of dial readings with different concentration of HBPA in different shear rate before and 


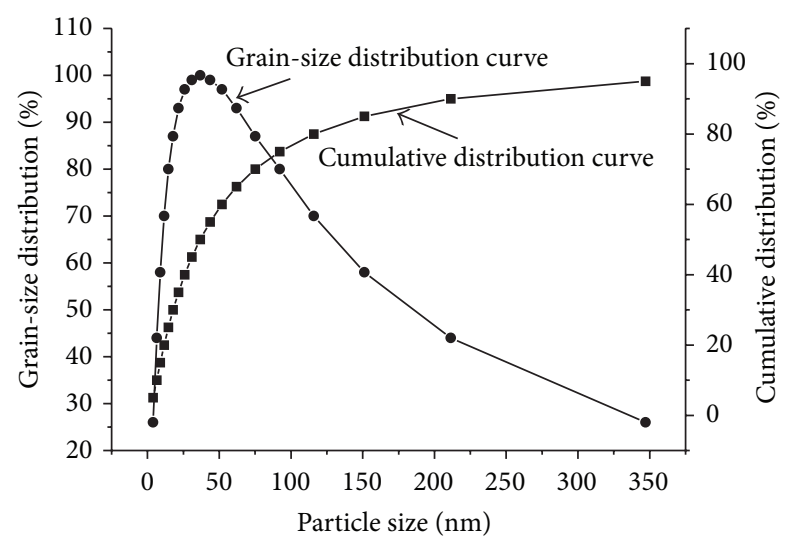

FIGURE 5: The grain size distribution and cumulative distribution of HBPA as nanoplugging polymer.

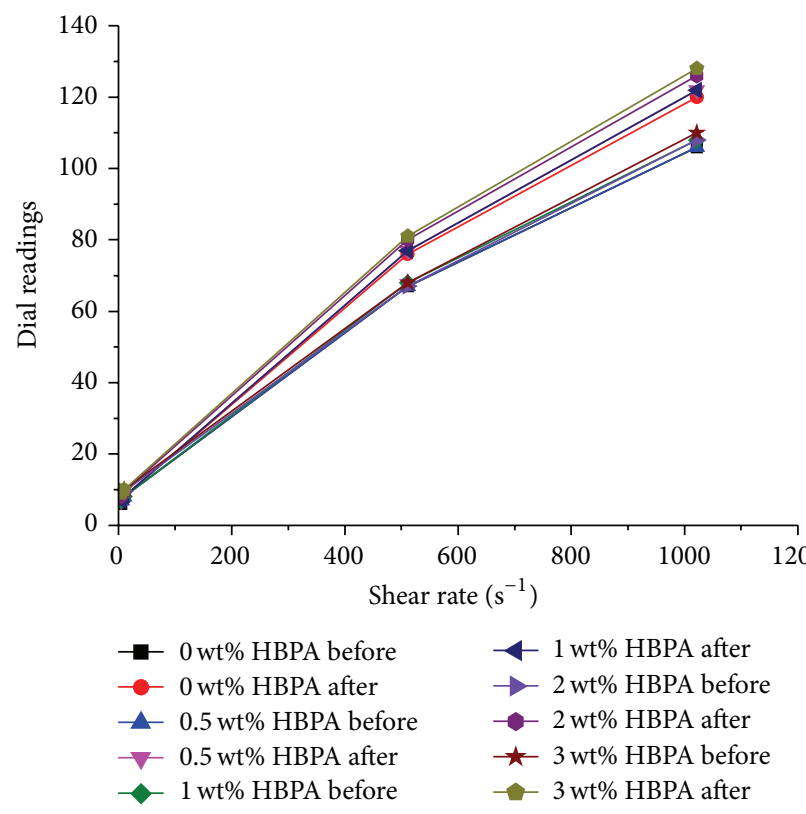

FIGURE 6: The change of dial readings with different concentration of HBPA in different shear rate before and after the thermal aging tests at $180^{\circ} \mathrm{C}$ for $16 \mathrm{~h}$.

after the thermal aging tests at $180^{\circ} \mathrm{C}$ for $16 \mathrm{~h}$ was shown in Figure 6 . With the increase of HBPA, dial reading of drilling fluid is only increased a little before the thermal aging tests at $180^{\circ} \mathrm{C}$ for $16 \mathrm{~h}$; that is, drilling fluid viscosity has a little change, which indicated that the HBPA has a little impact on the rheological properties of drilling fluid. Compared with the dial readings of drilling fluid without HBPA after the thermal aging tests at $180^{\circ} \mathrm{C}$ for $16 \mathrm{~h}$, when HBPA is less than $1 \mathrm{wt} \%$, dial reading has only a little increase with the increase of HBPA; that is, drilling fluid viscosity has almost no change. When HBPA is greater than $1 \mathrm{wt} \%$, the dial reading increases slightly; that is, drilling fluid viscosity increased slightly. The results fully embody the physical chemistry properties of low viscosity of hyperbranched polymer and have a little impact on the rheological properties of drilling fluid before and after the thermal aging tests at $180^{\circ} \mathrm{C}$ for $16 \mathrm{~h}$.

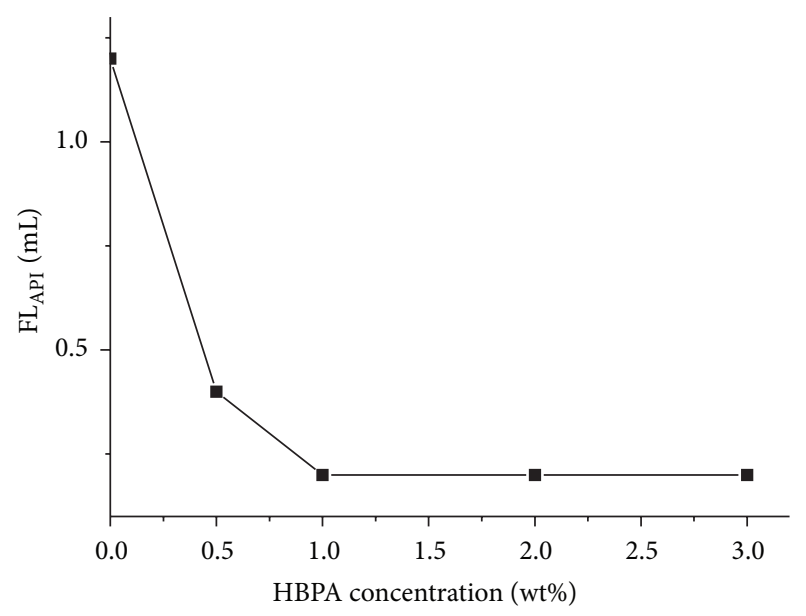

FIGURE 7: The effect of HBPA concentration on the API filtrate volume $\left(\mathrm{FL}_{\mathrm{API}}\right)$ after thermal aging tests at $180^{\circ} \mathrm{C}$ for $16 \mathrm{~h}$.

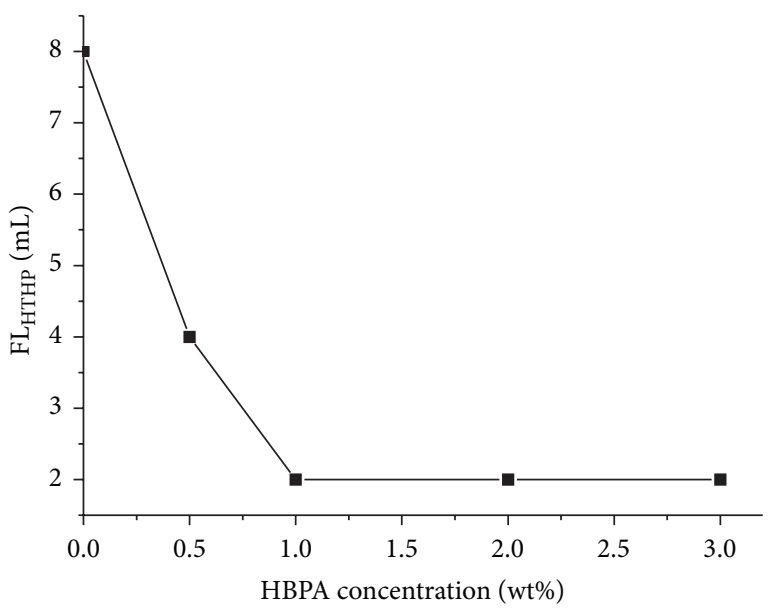

FIGURE 8: The effect of HBPA concentration on the $\mathrm{FL}_{\mathrm{HTHP}}$ after thermal aging tests at $180^{\circ} \mathrm{C}$ for $16 \mathrm{~h}$.

Rheological and filtrate properties of oil-based drilling fluid with different concentrations of HBPA before and after hot rolling test at $180^{\circ} \mathrm{C}$ for $16 \mathrm{~h}$ are shown in Table 1 . Before and after hot rolling test, all the rheological data, including $\mathrm{AV}, \mathrm{PV}$, and YP, have almost a very small increase. Emulsionbreaking voltage has a little increase, which is beneficial to maintain stability of oil-based drilling fluid. It can be inferred that HBPA has little effect on the rheological properties of oil-based drilling fluid because of hyperbranched polymers having very low viscosity. The filtrate volume of $\mathrm{FL}_{\mathrm{API}}$ and $\mathrm{FL}_{\mathrm{HTHP}}$ after the thermal aging tests at $180^{\circ} \mathrm{C}$ for $16 \mathrm{~h}$ was shown in Figures 7 and 8, respectively. It showed that HBPA can decrease dramatically the $\mathrm{FL}_{\mathrm{API}}$ and $\mathrm{FL}_{\mathrm{HTHP}}$ with the increase of HBPA concentration after thermal aging tests. When the dosage of HBPA is greater than $1 \mathrm{wt} \%$, the filtrate volume of $\mathrm{FL}_{\mathrm{HTHP}}$ has not changed. Therefore, the optimum added amount of HBPA is $1 \mathrm{wt} \%$.

3.5.2. Plugging Effect Evaluation. Kumar uses kind of gradually narrow wedge grooves to simulate the formation fracture. 
TABLE 1: Rheological behaviors of oil-based drilling fluid under different HBPA concentrations (before and after the thermal aging tests at $180^{\circ} \mathrm{C}$ for $\left.16 \mathrm{~h}\right)$.

\begin{tabular}{lcccccccccc}
\hline \multirow{2}{*}{ HBPA concentration (wt\%) } & \multicolumn{2}{c}{ AV (MPas) } & \multicolumn{2}{c}{ PV (MPa·s) } & \multicolumn{2}{c}{ YP (Pa) } & \multicolumn{2}{c}{ GEL (Pa/Pa) } & \multicolumn{2}{c}{ ES (V) } \\
& Before & After & Before & After & Before & After & Before & After & Before & After \\
\hline 0 & 53 & 60 & 39 & 44 & 14 & 16 & $4 / 8$ & $4 / 9$ & 1255 & 1345 \\
0.5 & 53 & 61 & 39 & 45 & 14 & 16 & $4 / 9$ & $5 / 10$ & 1258 & 1355 \\
1 & 54 & 61 & 40 & 45 & 14 & 16 & $4 / 9$ & $5 / 10$ & 1262 & 1364 \\
2 & 54 & 63 & 41 & 46 & 13 & 17 & $4 / 10$ & $5 / 11$ & 1268 & 1372 \\
3 & 55 & 64 & 42 & 47 & 13 & 17 & $4 / 10$ & $5 / 11$ & 1275 & 1380 \\
\hline
\end{tabular}

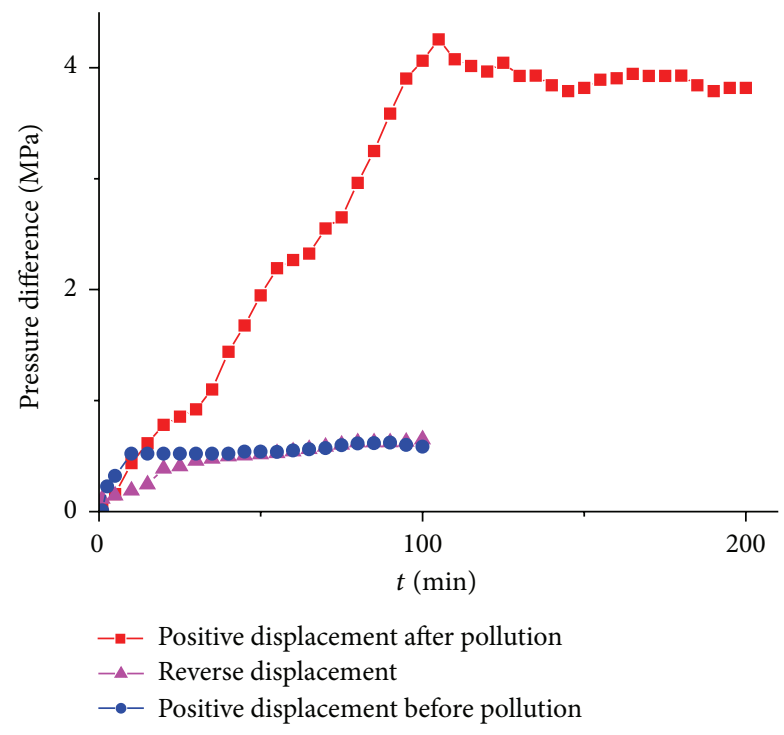

FIGURE 9: The displacement pressure curve of oil-based drilling fluid for artificial core without HBPA.

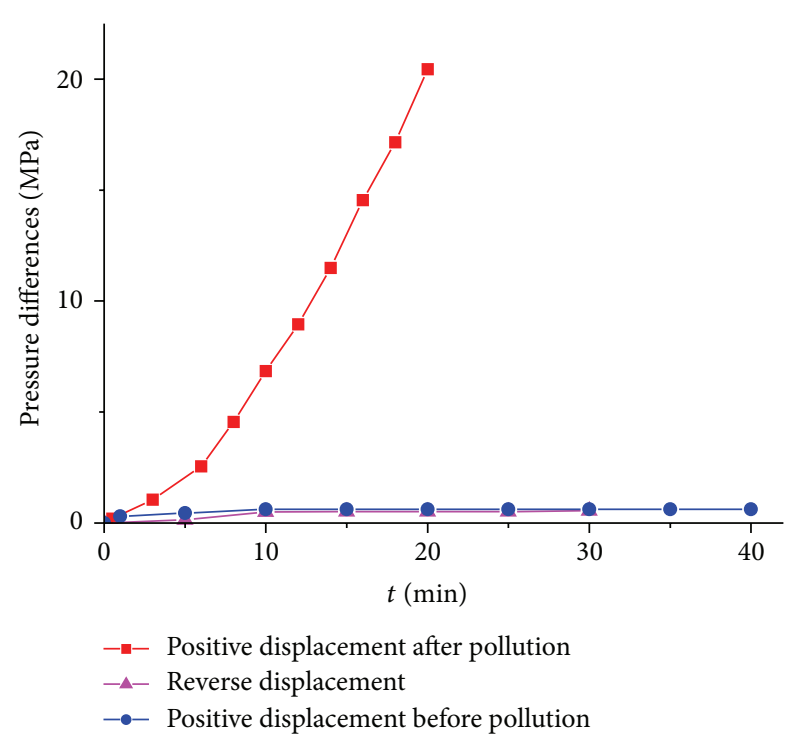

FIgURE 10: The displacement pressure curve of oil-based drilling fluid for artificial core with $1 \mathrm{wt} \%$ HBPA.
Pressure conditions and plugging performance of the fiber and solid particles for fracture were evaluated [26, 27]. The groove diameter is $1000 \sim 2500 \mu \mathrm{m}$ and the width of another metal cutting board is tens of microns. However, microcracks and pore in shale formation are usually nanoscale. The above two kinds of models are not suitable for the simulation of shale microcracks. Therefore, artificial core with a low permeability of $10 \times 10^{-3} \mu \mathrm{m}^{2}$ was utilized to simulate the formation fracture. Permeability and displacement pressure curve of artificial core were determined by permeability test equipment and pressure sensor, respectively. The displacement pressure curve was illustrated in Figures 9 and 10. Figure 9 is the displacement pressure curve of oil-based drilling fluid without HBPA. Figure 9 shows that the pressure peak of positive displacement is only $0.62 \mathrm{MPa}$ before pollution by oil-based drilling fluid without HBPA. The pressure peak of positive displacement is about $4.05 \mathrm{MPa}$ and the pressure peak of reverse displacement is about $0.65 \mathrm{MPa}$ after pollution by oil-based drilling fluid without HBPA. Figure 10 is the displacement pressure curve of oil-based drilling fluid with $1 \mathrm{wt} \%$ HBPA. Figure 10 shows that the pressure peak of positive displacement is only $0.62 \mathrm{MPa}$ before pollution by oil-based drilling fluid with $1 \mathrm{wt} \% \mathrm{HBPA}$. The pressure peak of positive displacement is about $20.45 \mathrm{MPa}$ and the pressure peak of reverse displacement is about $0.55 \mathrm{MPa}$ after pollution by oil-based drilling fluid with $1 \mathrm{wt} \%$ HBPA. Plugging rate of oil-based drilling fluid through formulas (1) and (2) is close to $100 \%$ after adding $1 \mathrm{wt} \%$ HBPA. The permeability recovery value can reach $99.7 \%$, which prove that HBPA has an excellent plugging performance:

$$
K=\frac{h \mu Q_{t}}{A \Delta P}
$$

$K$ is the permeability of artificial core, $10^{-5} \mu \mathrm{m}^{2} . A$ is the cross-sectional area of artificial core, $\mathrm{cm}^{2} . \Delta P$ is the differential pressure, $\mathrm{MPa} . h$ is the core length, $\mathrm{cm} . \mu$ is the viscosity of oil-based drilling fluid, MPa.s. $Q_{t}$ is the average flow rate, $\mathrm{cm}^{3} \cdot \mathrm{s}^{-1}$. Consider the following:

$$
W=\frac{\left(K_{1}-K_{2}\right)}{K_{1}} \times 100 \% .
$$

$W$ is the plugging rate of oil-based drilling fluid, $1 . K_{1}$ is the permeability of artificial core after pollution by oilbased drilling fluid without HBPA. $K_{2}$ is the permeability of 
artificial core after pollution by oil-based drilling fluid with $1 \mathrm{wt} \%$ HBPA.

\section{Conclusion}

The hyperbranched polyamine was synthesized by selfcondensing vinyl polymerization with divinyl sulfone, $\mathrm{N}$ phenyl-p-phenylenediamine, by an $\mathrm{A}_{2}+\mathrm{BB}_{2}^{\prime}$ method. The hyperbranched polyamine was characterized by FT-IR, phase analysis light scanning, and TGA methods. Hyperbranched polyamine as nanoplugging agent was successfully applied in the oil-based drilling fluid system.

Grain size distribution of HBPA is in the range of 3 $350 \mathrm{~nm}$ and the average grain diameter is $36.7 \mathrm{~nm}$ by phase analysis light scattering. The grain size of polymer particles smaller than $100 \mathrm{~nm}$ accounted for $80 \%$ and the grain size distribution is wide, which can block the microfracture of different nanoscale. HBPA has a good thermal stability and the decomposition temperature is greater than 299.

Artificial core with a low permeability was utilized to simulate the shale formation. When hyperbranched polyamine was added into the oil-based drilling fluid system, the permeability of artificial core declines sharply with the increase of concentration. When the HBPA concentration is greater than $1 \mathrm{wt} \%$, the plugging effect of HBPA is the best and the emulsion-breaking voltage has a slight increase. HBPA has a negligible effect on rheological properties of oil-based drilling fluid and decreases dramatically the $\mathrm{FL}_{\mathrm{API}}$ and $\mathrm{FL}_{\mathrm{HTHP}}$. In conclusion, hyperbranched polyamine was an excellent nanoplugging agent, which was expected to solve the problem of shale borehole wall instability.

\section{Conflict of Interests}

The authors declare that there is no conflict of interests regarding the publication of this paper.

\section{Acknowledgments}

This work was financially supported by National Science and Technology Major Projects in China "Study on Deep Well Drilling Fluid and Cementing Technology of High Temperature and High Pressure under Complicated Geological Conditions" (2011ZX05021-004) and Science and Technology Research and Technology Development Projects of China National Petroleum Corporation "The key technology research of basic theory of wellbore liquid” (2014A-4212).

\section{References}

[1] M. Khodja, J. P. Canselier, F. Bergaya et al., "Shale problems and water-based drilling fluid optimisation in the Hassi Messaoud Algerian oil field," Applied Clay Science, vol. 49, no. 4, pp. 383393, 2010.

[2] G. M. Bol, S.-W. Wong, C. J. Davidson, and D. C. Woodland, "Borehole stability in shales," SPE Drilling \& Completion, vol. 9, no. 2, pp. 87-94, 1994.

[3] A. Dzialowski, A. Hale, and S. Mahajan, "Lubricity and wear of shale: effects of drilling fluids and mechanical parameters," in Proceedings of the SPE/IADC Drilling Conference, Society of Petroleum Engineers, Amsterdam, The Netherlands, February 1993.

[4] M. K. Chaudhury, "Complex fluids: spread the word about nanofluids," Nature, vol. 423, no. 6936, pp. 131-132, 2003.

[5] J. Abdo and M. D. Haneef, "Nano-enhanced drilling fluids: pioneering approach to overcome uncompromising drilling problems," Journal of Energy Resources Technology, vol. 134, no. 1, Article ID 014501, 6 pages, 2012.

[6] L. Li, X. Xu, J. Sun, X. Yuan, and Y. Li, "Vital role of nanomaterials in drilling fluid and reservoir protection applications," in Proceedings of the Abu Dhabi International Petroleum Conference and Exhibition, Society of Petroleum Engineers, Abu Dhabi, UAE, November 2012.

[7] S. Ali, M. Luyster, A. Patel, C. Svoboda, R. McCarty, and B. Pearl, "Reversible drilling fluid emulsions for improved well performance," Oilfield Review, vol. 16, no. 3, pp. 62-68, 2004.

[8] C. Temple, A. Youngson, and C. P. Wain, "Drilling fluids with improved shale inhibition and methods of drilling in subterranean formations," USA Patent WO2005078047, 2005.

[9] S. T. Jayanth and Z. B. Malgorzata, "An experimental investigation on use of nanoparticles as fluid loss additives in a surfactant-polymer based drilling fluids," in Proceedings of the International Petroleum Technology Conference, ITPC 14952, Bangkok, Thailand, November 2011.

[10] T. Sensoy, M. E. Chenevert, and M. M. Sharma, "Minimizing water invasion in shales using nanoparticles," in Proceedings of the SPE Annual Technical Conference and Exhibition, SPE124429-MS, New Orleans, La, USA, October 2009.

[11] J. Cai, M. E. Chenevert, M. M. Sharma, and J. Friedheim, "Decreasing water invasion into Atoka shale using nonmodified silica nanoparticles," SPE Drilling and Completion, vol. 27, no. 1, pp. 103-112, 2012.

[12] D. V. Kosynkin, G. Ceriotti, K. C. Wilson et al., "Graphene oxide as a high-performance fluid-loss-control additive in waterbased drilling fluids," ACS Applied Materials \& Interfaces, vol. 4, no. 1, pp. 222-227, 2012.

[13] M. C. Li, Q. Wu, K. Song, Y. Qing, and Y. Wu, "Cellulose nanoparticles as modifiers for rheology and fluid loss in bentonite water-based fluids," ACS Applied Materials \& Interfaces, vol. 7, no. 8, pp. 5006-5016, 2015.

[14] M.-C. Li, Q. Wu, K. Song, S. Lee, Y. Qing, and Y. Wu, "Cellulose nanoparticles: structure-morphology-rheology relationships," ACS Sustainable Chemistry \& Engineering, vol. 3, no. 5, pp. 821832, 2015.

[15] T. Zhang, A. Davidson, S. L. Bryant, and C. Huh, "Nanoparticlestabilized emulsions for applications in enhanced oil recovery," in Proceedings of the SPE Improved Oil Recovery Symposium, SPE Paper 129885, Tulsa, Okla, USA, April 2010.

[16] D. Espinosa, F. Caldelas, K. Johnston, S. L. Bryant, and C. Huh, "Nanoparticle-stabilized supercritical $\mathrm{CO}_{2}$ foams for potential mobility control applications," in Proceedings of the 17th Improved Oil Recovery Symposium (IOR '10), vol. 129925 of SPE paper, pp. 1242-1254, Tulsa, Okla, USA, April 2010.

[17] B. Hughes, Sealant Improves Drilling in Depleted Sands, Drilling Contractor, 2006.

[18] D. Yan, C. Gao, and H. Frey, Hyperbranched Polymers: Synthesis, Properties, and Applications, John Wiley \& Sons, 2011.

[19] C. Gao and D. Yan, "Hyperbranched polymers: from synthesis to applications," Progress in Polymer Science, vol. 29, no. 3, pp. 183-275, 2004. 
[20] Recommended Practice, Standard Procedure for Field Testing Drilling Fluids, vol. 13B, API, Washington, DC, USA, 12th edition, 1988.

[21] C. Gao and D. Yan, "Polyaddition of $\mathrm{B}_{2}$ and $\mathrm{BB}_{2}$ type monomers to $\mathrm{A}_{2}$ type monomer. 1. Synthesis of highly branched copoly(sulfone-amine)s," Macromolecules, vol. 34, no. 2, pp. 156-161, 2001.

[22] S. S. Mahapatra and N. Karak, "Hyperbranched polyamine: a promising curing agent for a vegetable oil-based poly(esteramide) resin," Progress in Organic Coatings, vol. 60, no. 4, pp. 328-334, 2007.

[23] R. M. Silverstein, G. C. Bassler, and T. C. Morril, Spectrometric Identification of Organic Compounds, Wiley, New York, NY, USA, 6th edition, 1998.

[24] J. C. Thomas, B. J. Crosby, R. I. Keir, and K. L. Hanton, "Observation of field-dependent electrophoretic mobility with phase analysis light scattering (PALS)," Langmuir, vol. 18, no. 11, pp. 4243-4247, 2002.

[25] J. F. Miller, K. Schätzel, and B. Vincent, "The determination of very small electrophoretic mobilities in polar and nonpolar colloidal dispersions using phase analysis light scattering," Journal of Colloid And Interface Science, vol. 143, no. 2, pp. 532$554,1991$.

[26] S. Savari, A. Kumar, D. L. Whitfill, and D. E. Jamison, "Improved lost circulation treatment design and testing techniques minimizes formation damage," in Proceedings of the SPE European Formation Damage Conference, SPE-143603-MS, Society of Petroleum Engineers, Noordwijk, The Netherlands, June 2011.

[27] K. Sandeep, S. Sharath, and D. E. Jamison, "Novel rheological tool to determine lost circulation materials plugging performance," in Proceedings of the North Africa Technical Conference and Exhibition, SPE 150726, Cairo, Egypt, February 2012. 

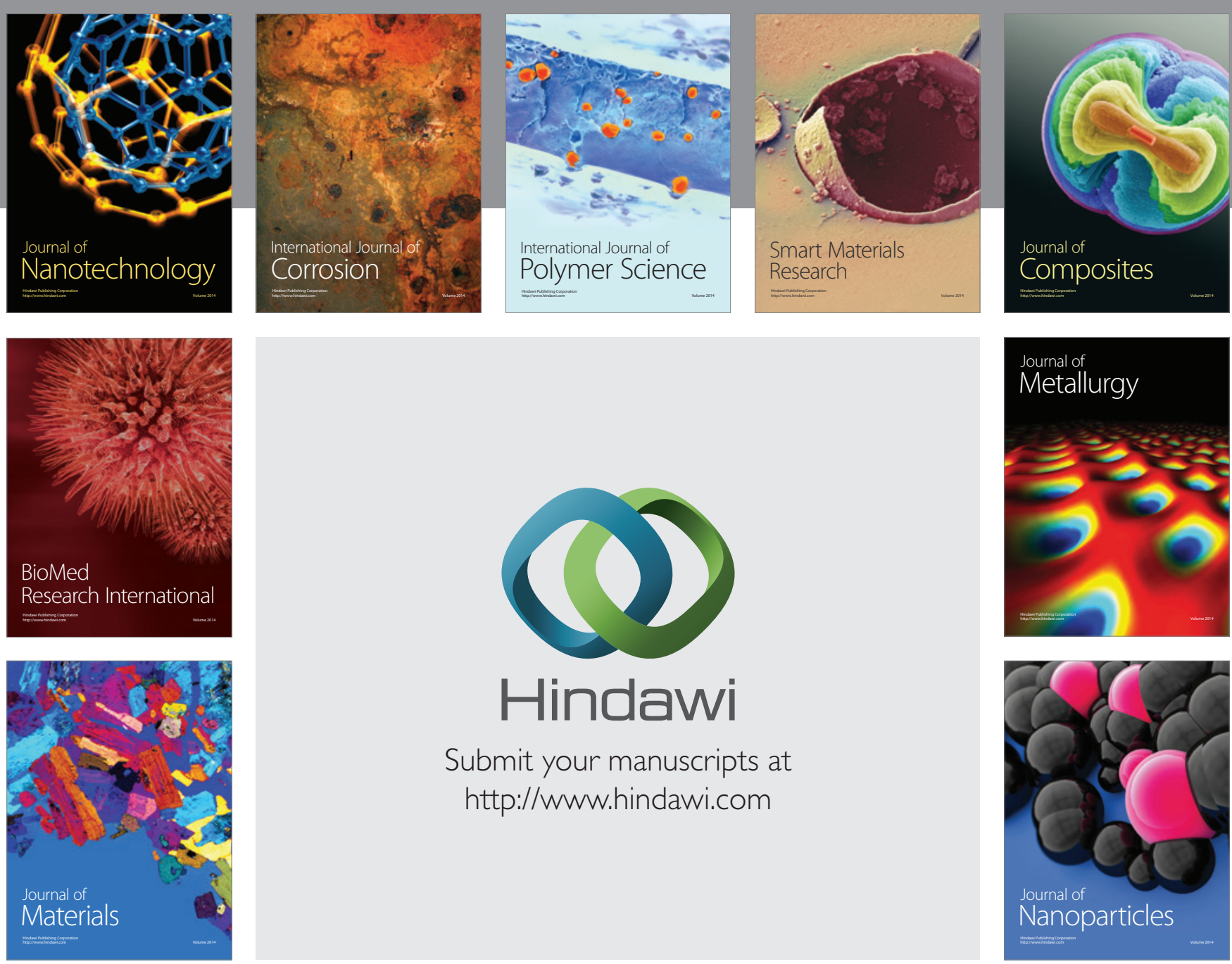

Submit your manuscripts at http://www.hindawi.com
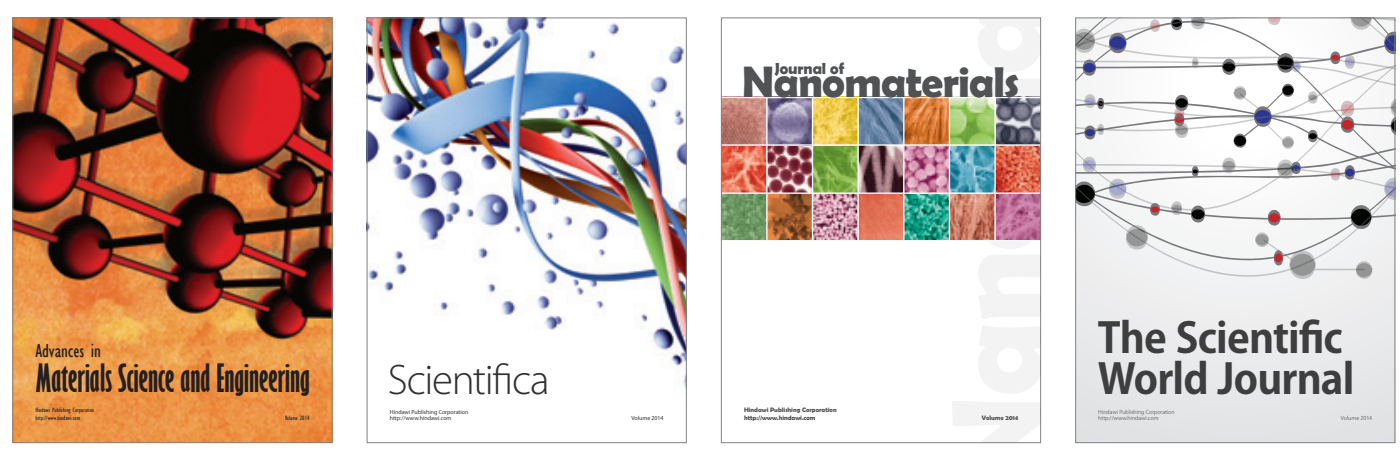

\section{The Scientific World Journal}
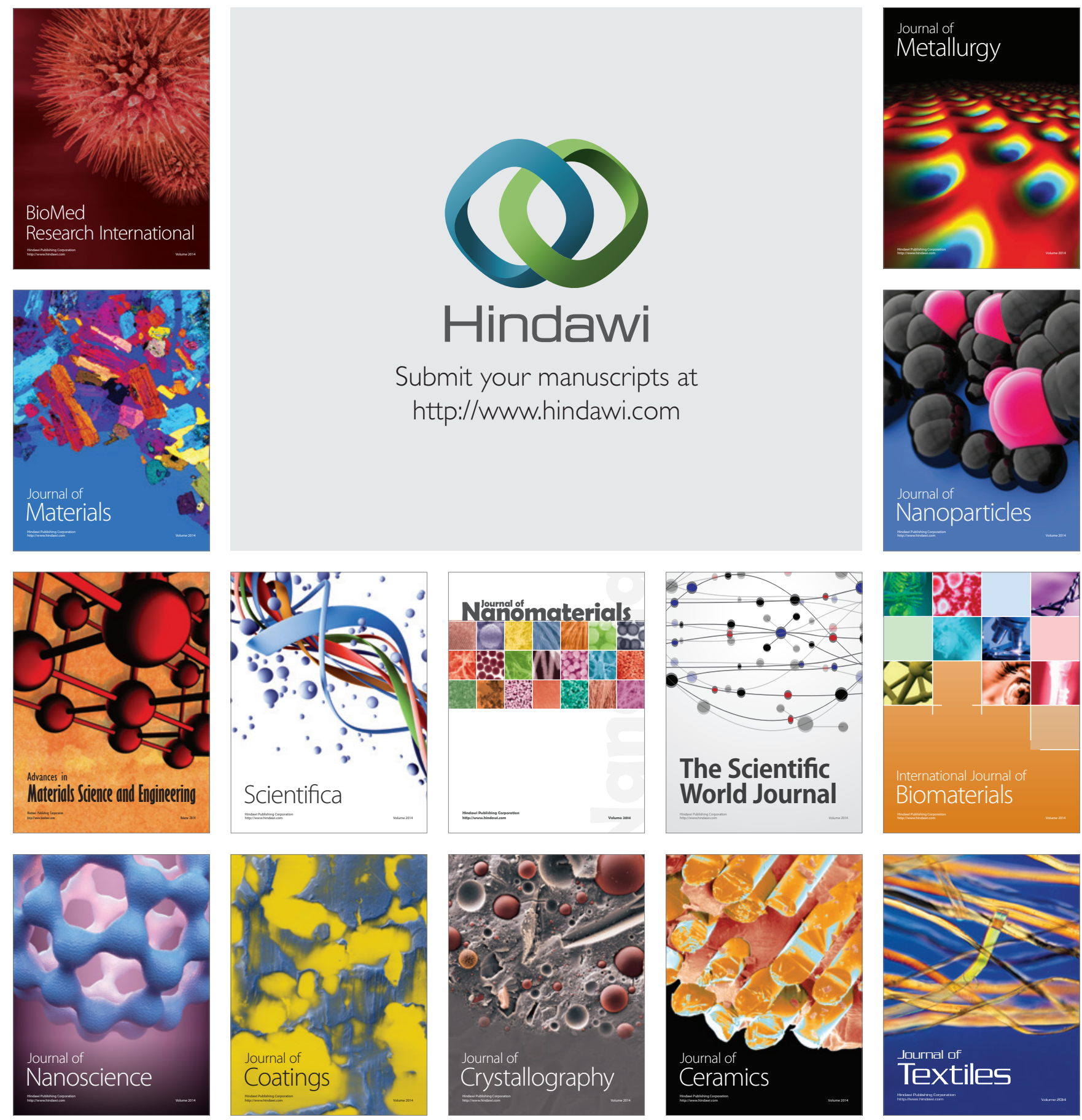